ORIGINAL ARTICLE

\title{
Recreational injuries among older Americans, 2001
}

\author{
L W Gerson, J A Stevens
}

Injury Prevention 2004;10:134-138. doi: 10.1136/ip.2004.005256

Objective: To describe the epidemiology of non-fatal recreational injuries among older adults treated in United States emergency departments including national estimates of the number of injuries, types of recreational activities, and diagnoses.

Methods: Injury data were provided by the National Electronic Injury Surveillance System-All Injury Program (NEISS-AIP), a nationally representative subsample of 66 out of 100 NEISS hospitals. Potential

See end of article for authors' affiliations

....................

Correspondence to: Dr L W Gerson, Division of Community Health

Sciences, Northeastern

Ohio Universities College

of Medicine, PO Box 95,

Rootstown, $\mathrm{OH}$

44272-0095, USA;

lgerson@neoucom.edu cases were identified using the NEISS-AIP definition of a sport and recreation injury. The authors then reviewed the two line narrative to identify injuries related to participation in a sport or recreational activity among men and women more than 64 years old.

Results: In 2001, an estimated 62164 (95\% confidence interval 35570 to 88758 ) persons $\geqslant 65$ years old were treated in emergency departments for injuries sustained while participating in sport or recreational activities. The overall injury rate was 177.3/100 000 population with higher rates for men $(242.5 / 100000)$ than for women (151.3/100 000). Exercising caused $30 \%$ of injuries among women and bicycling caused $17 \%$ of injuries among men. Twenty seven percent of all treated injuries were fractures and women (34\%) were more likely than men (21\%) to suffer fractures.

Conclusions: Recreational activities were a frequent cause of injuries among older adults. Fractures were common. Many of these injuries are potentially preventable. As more persons engage in recreational activities, applying known injury prevention strategies will help to reduce the incidence of these injuries. t is well known that the demographics of the United States population are changing due to the growing proportion of older Americans. ${ }^{1}$ It is also well known that regular physical activity throughout life is important for maintaining a healthy body, enhancing psychological wellbeing, and preventing premature death. ${ }^{2}{ }^{3}$ Injuries are an unintended consequence of physical activity. Little is known about sport and recreational injuries (referred to as recreational injuries in this paper), particularly among older persons. This paper describes recreational injuries among older adults age $\geqslant 65$ years.

Increasing physical activity among all Americans is a national health goal and there have been successful efforts to improve rates of participation. ${ }^{4}$ A Healthy People 2010 (HP2010) objective for the United States is to raise to $30 \%$ the proportion of all Americans who engage in moderate physical activity for 30 minutes at least five times a week. The 1997 baseline showed 15\% of Americans, including 14\% of older Americans, met this goal. ${ }^{5}$ One significant effort to achieve this objective is the National Blueprint, Increasing Physical Activity Among Adults Age 50 and Older. ${ }^{6}$ This proposal was developed by a collaboration of governmental and private organizations interested in physical fitness and aging. Implementation will lead to greater numbers of older persons engaging in physical activity. While increased physical activity will have an overall positive effect on health, it also will increase exposure to the possibility of injury.

We know very little about recreational injuries, especially among older adults. Gotsch et al analyzed National Electronic Injury Surveillance System-All Injury Program (NEISS-AIP) data and reported that during July 2000 to June 2001 there were 4.3 million recreational injuries treated in United States emergency departments. ${ }^{7}$ The recreational injury rate for persons $\geqslant 45$ years old was 4.3/1000 for men and 2.2/1000 for women. ${ }^{7}$ However, these authors did not examine injury rates for adults age $\geqslant 65$ years. Hootman and colleagues surveyed a select population of seniors that included 1569 community dwelling persons $\geqslant 60$ years old who were enrolled in a preventive medicine clinic exercise program. They found that $17.5 \%$ of the respondents reported they had sustained an activity related lower extremity injury to soft tissue or bone. ${ }^{8}$ For the general population of older persons, many of whom are not engaged in fitness activities, the recreational injury rate likely is markedly lower.

The rapid growth in the proportion of Americans age $\geqslant 65$ years old suggests that the number of recreational injuries treated in emergency departments will grow if efforts at increasing physical activity among older Americans succeed. It is important to characterize recreational injuries to help us understand the activities associated with higher risk for injury and the mechanisms of injury so that strategies can be developed and implemented to prevent these injuries. In this paper, we analyzed NEISS-AIP data to describe non-fatal recreational injuries among older adults treated in emergency departments and provide national estimates of the number of injuries, types of recreational activities, and diagnoses.

\section{METHODS}

We analyzed data from the NEISS-AIP from 1 January 2001 to 31 December 2001 to estimate the number and rate of recreational injuries among older adults in the United States (defined as adults age $\geqslant 65$ ). The Northeastern Ohio Universities College of Medicine Institutional Review Board exempted this secondary analysis of public data from review.

NEISS-AIP is operated by the United States Consumer Product Safety Commission and collects data on initial visits for all types and causes of injuries treated in United States emergency departments. ${ }^{9}$ NEISS-AIP data are drawn from a nationally representative subsample of 66 out of 100 NEISS hospitals, selected as a stratified probability sample of hospitals in the United States and its territories with a minimum of six beds and a 24 hour emergency department. NEISS-AIP provides data on approximately 500000 injury

Abbreviations: $\mathrm{Cl}$, confidence interval; NEISS-AIP, National Electronic Injury Surveillance System-All Injury Program 
and consumer product related emergency department cases each year.

Each case was assigned a sample weight based on the inverse probability of the hospital being selected. Confidence intervals (CIs) were calculated by using a direct variance estimation procedure that accounted for the sample weights and complex sample design. Rates were calculated by using 2001 United States Census Bureau population estimates.

NEISS-AIP defines a recreational injury as one occurring during organized and unorganized activity whether or not work or product related. Injury is defined as bodily harm resulting from exposure to an external substance. NEISS classified each case into one of 39 mutually exclusive sport/ recreation categories (see box 1 ) based on an algorithm that included the consumer product involved (for example, bicycle or golf cart) and a two line description of the event. Falls occurring on pool decks were classed as recreational injury when there was clear evidence from the two line summary that the person was swimming. Golf carts are battery powered four wheel vehicles frequently used for transportation of players and equipment during golf matches. Their use is mandatory on many courses that cater to retirees. They also are used for transportation in retirement communities and elsewhere. We classified golf cart injuries as recreational unless there was clear evidence that it was not. We elected to define all falls while walking as recreational injuries.

Cases were excluded if the cause was violence related or the principal diagnosis was illness. Also excluded were cases of pain only, psychological harm only, contact dermatitis, adverse effect of surgery or therapeutic drugs, or the patient was dead on arrival or died in the emergency department.

Potential cases in our analyses were $\geqslant 65$ years old and initially identified using the NEISS-AIP definition of a recreational injury. The authors then independently reviewed the two line narrative and identified injuries related to participation in a recreational activity. Differences were discussed and resolved.

Excluded cases were those that:

- Involved sports/recreation equipment or apparel but had no evidence in the narrative that the person was engaged in a recreational activity at the time the injury occurred (for example, was moving or repairing equipment, had equipment fall on them, was injured near a swimming pool with no evidence of swimming).

- Involved a powered scooter, a four wheeler or all-terrain vehicle at home because these were regarded primarily as forms of transportation.

- Resulted from, or was incidental to, a "grand parenting activity" (for example, struck by a child who fell off a swing).

Also excluded were cases in which the person was a spectator at a sport or recreational event or when an injury was related to an occupational activity.

\section{RESULTS}

There were an estimated 62164 (95\% CI 35570 to 88758 ) persons $\geqslant 65$ years old treated in emergency departments for injuries sustained while participating in recreational activities. Six thousand two hundred (10\%, 95\% CI 5.8\% to $14.2 \%$ ) of these were hospitalized. Table 1 shows that the injury rate for men was $60 \%$ higher than the rate for women, and the rates for both sexes decreased as age increased. Forty percent (95\% CI $6.4 \%$ to $73.8 \%$ ) of the injuries occurred in a sports venue, $13 \%$ at home, and $11 \%$ in the street (data not shown).

Figure 1 depicts the distribution of activities associated with non-fatal recreational injuries for men and women. Approximately $70 \%$ of injuries occurred as a result of five
Box 1: Categories of sport/recreational injury

- Amusement attraction.

- All-terrain vehicle.

- Baseball.

- Basketball.

- Bicycle.

- Billiards.

- Bowling.

- Camping.

- Combative.

- Exercise.

- Fishing.

- Football.

- Go-kart.

- Golfing.

- Gymnastics.

- Hockey.

- Horseback.

- Miscellaneous ball games.

- Moped/powered minibike/off*.

- Non-powder gun.

- Personal watercraft.

- Playground.

- Racquet sports.

- Scooter.

- Skateboarding.

- Skating, ice.

- Skating, in-line.

- Skating, other.

- Snow skiing.

- Snowmobile.

- Soccer.

- Softball.

- Swimming.

- Toboggan/sled/disk.

- Tack and field.

- Trampoline.

- Volleyball.

- Waterskiing/surfing.

- Other, specify.

*Two wheeled off-road powered vehicles including dirt bikes and trail bikes.

categories of activity: bicycling, exercising, fishing, golfing, and snow skiing. However, older men and women were injured in a wide variety of activities as seen by the large proportion characterized as "other" injuries (see box 1). Exercise was the activity most often associated with injury occurrence. Thirty percent of women and 16\% of men were injured while exercising (which included walking, running, Tai Chi, equipment, and exercise classes). Bicycling, snow skiing, and exercise were virtually equal as sources of injury for men, closely followed by golf and fishing. Bicycling was the second leading source of recreational injuries among women. Snow skiing ranked fourth for women, but the frequency was similar to bicycling and golf. Fishing was a common source of injuries for men but not for women. Most of the fishing injuries were foreign body (fishhook) injuries 


\begin{tabular}{|c|c|c|c|c|c|}
\hline $\begin{array}{l}\text { Patient } \\
\text { characteristic }\end{array}$ & Unweighted No & Weighted No & $95 \% \mathrm{Cl}$ & Rate/ 100000 & $95 \% \mathrm{Cl}$ \\
\hline Female & 317 & 26745 & 15147 to 38343 & 151.3 & 73.1 to 184.9 \\
\hline $65-74$ & 185 & 15953 & 7796 to 24110 & 160.5 & 77.8 to 240.6 \\
\hline $75-84$ & 106 & 8936 & 5385 to 12487 & 120.3 & 71.0 to 164.6 \\
\hline $85+$ & 26 & 1856 & 642 to 3070 & 60.1 & 20.5 to 98.2 \\
\hline Male & 436 & 35420 & 19790 to 51049 & 242.5 & 135.8 to 349.2 \\
\hline $65-74$ & 308 & 25247 & 13329 to 37166 & 307.2 & 160.6 to 447.7 \\
\hline $75-84$ & 116 & 9295 & 5404 to 13186 & 184.3 & 108.2 to 263.9 \\
\hline $85+$ & 12 & 877 & 338 to 1416 & 65.1 & 25.6 to 107.2 \\
\hline Total & 753 & 62164 & 35570 to 88758 & 177.3 & 100.6 to 251.1 \\
\hline $65-74$ & 493 & 41200 & 21516 to 60885 & 226.9 & 117.4 to 332.3 \\
\hline $75-84$ & 222 & 18231 & 11324 to 25138 & 146.2 & 90.0 to 199.8 \\
\hline $85+$ & 38 & 2733 & 1271 to 4185 & 61.6 & 28.8 to 94.1 \\
\hline
\end{tabular}

but exposure and insect bites were also sources of injuries. Many of the golf cart injuries common among men and women resulted from inappropriate operation of golf carts (for example, tipping on a slope, driving while impaired).

The single most common type of all non-fatal injuries treated in emergency departments was fracture (table 2). Fractures comprised $27 \%$ of all injuries and were more common among women. One third of women were treated for fractures compared with one fifth of men. Women also were more likely to suffer sprains and strains, the second leading injury diagnosis for both sexes. Internal injury was the least common consequence of recreational activities and occurred in less than $5 \%$ of all cases.

Table 3 presents the distribution of non-fatal injuries among different body sites. The pattern for location of injuries was similar for men and women. Extremities were the most common site and accounted for half of all injuries. While the overall picture is similar, it is worth noting that one third of injuries for women compared with one fifth of injuries for men were to the leg and foot.

\section{DISCUSSION}

To our knowledge, this is the first report of non-fatal recreational injuries sustained by older adults treated in emergency departments. The injuries sustained by persons in this study reflect the current population based rates of participation in sports and recreational activities by older adults. With the changing demographics and the promotion of physical activity, these rates will likely increase and recreational injuries among older adults will become a more pressing public health issue.

Older adults engaged in a variety of recreational activities. Exercise (including walking, equipment use, and exercise classes), bicycling, snow skiing, golf, and fishing were responsible for the majority of recreational injuries. These injuries ranged from serious that are associated with significant morbidity and mortality (for example, fractures) to minor that required little medical attention (for example, a fishhook in the finger).

While many injuries to older adults that are treated in the emergency department may appear to be minor, they may have important long term consequences. Such injuries can seriously affect an older person's ability to function independently. Shapiro and coworkers followed up a group of persons $\geqslant 65$ years old who were treated in the emergency department for minor injuries (including 26\% fracture.) They found that $7 \%$ of them had decreased scores in fundamental activities of daily living and $23 \%$ had decreased scores in instrumental activities of daily living. ${ }^{10}$

Older people are not commonly the focus of injury prevention programs. Given these results, it appears that designing injury prevention programs for older adults would
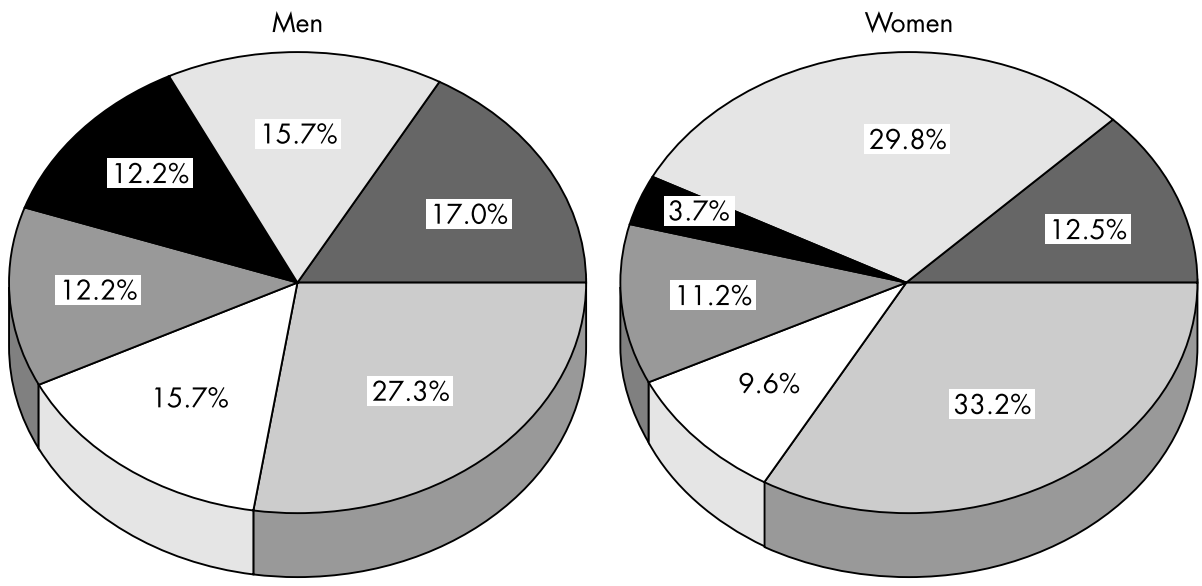

Figure 1 Distribution of activities that cause recreational injuries to persons $\geqslant 65$ by sex, United States, 2001.

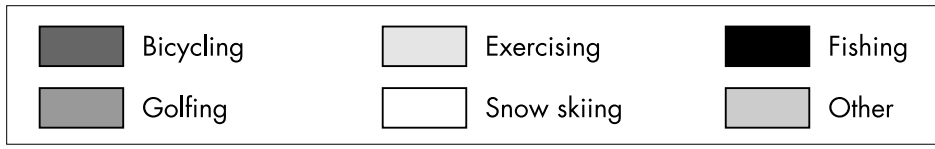




\begin{tabular}{|c|c|c|c|c|}
\hline Diagnosis & Unweighted No & Weighted No & $95 \% \mathrm{Cl}$ & $\%$ \\
\hline \multicolumn{5}{|l|}{ Male } \\
\hline Contusion/abrasion & 73 & 5883 & 2678 to 9087 & 16.6 \\
\hline Fracture & 96 & 7449 & 3808 to 11091 & 21.1 \\
\hline Laceration & 47 & 4505 & 2470 to 6541 & 12.7 \\
\hline Internal injury & 29 & 1738 & 953 to 2524 & 4.9 \\
\hline Strain/sprain & 90 & 6937 & 2963 to 10912 & 19.6 \\
\hline Other & 100 & 8882 & 4355 to 13409 & 25.1 \\
\hline \multicolumn{5}{|l|}{ Female } \\
\hline Contusion/abrasion & 56 & 4144 & 2313 to 5974 & 15.6 \\
\hline Fracture & 101 & 8957 & 5082 to 12832 & 33.6 \\
\hline Laceration & 38 & 3320 & 1752 to 4888 & 12.5 \\
\hline Internal injury & 13 & 1059 & 207 to 1912 & 4.0 \\
\hline Strain/sprain & 71 & 6542 & 2201 to 10884 & 24.6 \\
\hline Other & 37 & 2611 & 1474 to 3748 & 9.8 \\
\hline \multicolumn{5}{|l|}{ Total } \\
\hline Contusion/abrasion & 129 & 10026 & 5320 to 14732 & 16.2 \\
\hline Fracture & 197 & 16406 & 9619 to 23193 & 26.5 \\
\hline Laceration & 85 & 7826 & 4531 to 11120 & 12.6 \\
\hline Internal injury & 42 & 2798 & 1357 to 4238 & 4.5 \\
\hline Strain/sprain & 161 & 13480 & 5494 to 21465 & 21.8 \\
\hline Other & 137 & 11493 & 6278 to 16708 & 18.5 \\
\hline
\end{tabular}

be worthwhile now-and probably more so in the future. Bicycling, a common source of recreational injuries, can be made safer through environmental modifications that separate bicycles from traffic. ${ }^{11}$ Such efforts will benefit cyclists of all ages. Wearing protective equipment when cycling is another effective injury prevention strategy, ${ }^{12}$ and older adults should be encouraged to adopt such safety measures. Operating golf carts inappropriately (for example, striking objects, tipping the cart, and attempting to board a moving cart) resulted in many recreational injuries. Strategies such as education programs that focus on using golf carts safely may reduce such injuries.

Our estimates of the number of recreational injuries among older adults are subject to some important limitations. First, we did not have information on how frequently older adults participated in the various recreational activities. Thus, we did not have the ability to calculate the true risk for the information that we reported. We used census data to calculate rates for population groups. Rates calculated with time engaged in an activity (exposure) as the denominator may reveal a different picture.

Second, the report included only non-fatal injuries treated in hospital emergency departments. We are missing injuries that were treated in physicians' offices, free standing medical centers or other clinics, those that did not require medical attention, and fatal injuries. People who are injured are likely to go to the emergency department for treatment. Injuries accounted for $37 \%$ of initial emergency department visits ${ }^{13}$ compared with about 7\% (56.4 million) of physician visits (including both initial treatment and follow up care). ${ }^{14}$ No doubt many of the office visits are to follow up care received in the emergency department. Additionally, Kinney and Gerson reported that in a Midwestern midsize city, $80 \%$ of persons who had a private physician were first treated for an injury at a free standing emergency medical center. ${ }^{15}$ This adds further support that private physicians' offices are often not the first place injured persons visit for treatment. We elected to focus on non-fatal injuries because information

Table 3 Number and percent distribution of body part injured for recreational injury to persons $\geqslant 65$ by sex, United States, 2001

\begin{tabular}{|c|c|c|c|c|}
\hline Body part injured & Unweighted No & Weighted No & $95 \% \mathrm{Cl}$ & $\%$ \\
\hline \multicolumn{5}{|l|}{ Male } \\
\hline Head/neck & 97 & 7842 & 4449 to 11234 & 22.3 \\
\hline Upper trunk & 72 & 6085 & 1465 to 10706 & 17.3 \\
\hline Lower trunk & 59 & 4026 & 2040 to 6011 & 11.4 \\
\hline Arm/hand & 104 & 9139 & 5859 to 12418 & 26.0 \\
\hline Leg/foot & 92 & 7273 & 4023 to 10523 & 20.7 \\
\hline Other & 10 & 816 & 21 to 1610 & 2.3 \\
\hline \multicolumn{5}{|l|}{ Female } \\
\hline Head/neck & 59 & 4353 & 2791 to 5916 & 16.3 \\
\hline Upper trunk & 27 & 2728 & 1108 to 4347 & 10.2 \\
\hline Lower trunk & 42 & 3658 & 1477 to 5839 & 13.7 \\
\hline Arm/hand & 79 & 7063 & 3956 to 10169 & 26.4 \\
\hline $\mathrm{Leg} /$ foot & 108 & 8893 & 4110 to 13675 & 33.2 \\
\hline Other & 2 & 50 & 0 to 117 & 0.2 \\
\hline \multicolumn{5}{|l|}{ Total } \\
\hline Head/neck & 156 & 12195 & 7898 to 16492 & 19.7 \\
\hline Upper trunk & 99 & 8813 & 3039 to 14586 & 14.2 \\
\hline Lower trunk & 101 & 7684 & 3821 to 11547 & 12.4 \\
\hline Arm/hand & 183 & 16202 & 10347 to 22056 & 26.2 \\
\hline $\mathrm{Leg} /$ foot & 200 & 16165 & 8362 to 23969 & 26.1 \\
\hline Other & 12 & 866 & 63 to 1668 & 1.4 \\
\hline
\end{tabular}




\section{Key points}

- This study is the first to focus on non-fatal recreational injuries among persons $\geqslant 65$ years old treated in emergency departments.

- Although many activities were responsible for injuries, bicycling and exercise were the largest contributors to the burden of injury. Fractures and sprains were the most common injuries.

- The lack of information about the frequency, duration, and intensity with which older adults engaged in these activities (exposure) seriously limited our ability to identify high risk activities.

- Accurately documenting the circumstances surrounding recreational injuries, including the use of protective devices, is crucial to our understanding both the sources of injuries and possible preventive interventions.

- We need to pay more attention to preventing sports and recreational injuries in this increasingly active population.

about deaths is not well captured by NEISS-AIP. Categorizing fatal recreational injuries would require details that are often missing in emergency department records of fatal events.

A third limitation was that the algorithm used to classify an injury relies on both the product involved and a two line description of the event. These descriptions often were sketchy and it was difficult to determine if the person was engaged in a recreational activity or if the event was classified as recreational because of the product. For example, there were a number of cases where a person fell on a pool deck. It was difficult to determine if the person was on the deck because they were swimming or they just happened to fall while on the deck for other reasons. We included as recreational injury only those cases in which there was clear evidence from the two line summary that the person was swimming. Similarly, for injuries that involved golf carts, it was not always clear whether the person was using the cart as part of a golf game or for transportation. We assumed that it was recreational unless there was clear evidence that it was not. Another difficult decision was if a fall occurred while walking. We elected to define all falls while walking as recreational injuries. Although we did our best to classify injuries, the limited information likely contributed to some misclassification.

NEISS-AIP is an important injury surveillance system. However, it is constrained by the information available in the medical record as well as the limited space provided by the two line narrative description. It would be helpful if information about the use of safety equipment were included in the medical record. It is important for emergency physicians to ask about use of protective equipment and to record whether it was used. In addition to recording valuable information, this interaction provides an opportunity for the physician to counsel the patient and family about safety and the importance of using protective equipment. Although only one complete year of data is currently available, NEISS-AIP will provide ongoing surveillance of recreational injuries and in future permit analyses of injury trends.

\section{CONCLUSIONS}

We described the epidemiology of recreational injuries among older adults treated in emergency departments. Older adults were injured while participating in a wide variety of recreational activities, particularly while bicycling and exercising. Fractures were common and women were more likely than men to suffer fractures. Many of these injuries are potentially preventable. As more persons engage in recreational activities, applying known injury prevention strategies will help to reduce the incidence of these injuries.

\section{ACKNOWLEDGEMENTS}

The authors would like to acknowledge Ms Patricia Holmgreen for her statistical assistance.

Portions of this paper were presented at the 7th World Conference on Injury Prevention and Control, Vienna, Austria, June 2004.

\section{Authors' affiliations}

L W Gerson, Northeastern Ohio Universities College of Medicine, Rootstown, Ohio, USA

J A Stevens, National Center for Injury Prevention and Control, Centers for Disease Control and Prevention, Atlanta, Georgia, USA

\section{REFERENCES}

1 Administration on Aging. Available at: http://www.aoa.gov/prof/Statistics/ statistics. asp (accessed 19 June 2003)

2 Lee IM, Paffenbarger RS Jr, Hennekens CH. Physical activity, physical fitness and longevity. Aging (Milano) 1997;9:2-11.

3 Gregg EW, Cauley JA, Stone K, et al. Relationship of changes in physical activity and mortality among older women. JAMA 2003;289:2379-86.

4 Kahn EB, Ramsey LT, Brownson RC, et al. The effectiveness of interventions to increase physical activity. A systematic review. Am J Prev Med 2002;22(4, suppl):73-107.

5 US Department of Health and Human Services. Healthy people 2010. 2nd Ed. Washington, DC: US Department of Health and Human Services, 2000 6 Anonymous. National blueprint: increasing physical activity among adults age 50 and older. Princeton, NJ: Robert Wood Johnson Foundation, 2001.

7 Gotsch K, Annest JL, Holmgreen P, et al. Nonfatal sports- and recreationrelated injuries treated in emergency departments: United States, July 2000June 2001. MMWR Morb Mortal Wkly Rep 2002;51:736-40.

8 Hootman JM, Macera CA, Ainsworth BE, et al. Epidemiology of musculoskeletal injuries among sedentary and physically active adults. Med Sci Sports Exerc 2002;34:838-44.

9 Schroeder T, Ault K. National Electronic Injury Surveillance System All Injury Program: sample design and implementation. Bethesda, MD: US Consumer Product Safery Commission, November 2001.

10 Shapiro MJ, Partridge RA, Jenouri I, et al. Functional decline in independent elders after minor traumatic injury. Acad Emerg Med 2001;8:78-81.

11 Pucher J, Dijkstra L. Promoting safe walking and cycling to improve public health: lessons from the Netherlands and Germany. Am J Public Health 2003:93:1509-16.

12 Thompson DC, Rivara FP, Thompson R, Helmets for preventing head and facial injuries in bicyclists. Cochrane Database of Systematic Reviews (2): CD001855, 2000.

13 McCaig LF, Ly N. National hospital ambulatory medical care survey: 2000 emergency department summary. Advance Data from Vital and Health Statistics; No 326. Hyattsville, MD: National Center for Health Statistics, 2002.

14 Cherry DK, Woodwell DA. National ambulatory medical care survey: 2000 summary. Advance Data from Vital and Health Statistics; No 328. Hyattsville, MD: National Center for Health Statistics, 2002.

15 Kinney TJ, Gerson L. Utilization of a freestanding emergency center by patients with and without private physicians. Ann Emerg Med 1983;12:762-4. 